\title{
Seroprevalence of Toxoplasma gondii IgG and IgM Antibodies and Associated Risks Factors in Tuberculosis Patients Admitted at the Bamenda Regional Hospital, NW Cameroon
}

\section{Noubom Michel ${ }^{1}$, Leonard Fonkeng Sama ${ }^{2,3 *}$, Oulianovie Guessom Kamgue ${ }^{4}$, Valery Pacome Tchenkam ${ }^{1}$, Elvis Chongsi Wam ${ }^{1,5,6}$ and Tume Christopher $\mathbf{B}^{1,7}$}

${ }^{1}$ Department of Biomedical Sciences, Faculty of Medical and pharmaceutical Sciences, University of Dschang, University of Dschang, Cameroon

${ }^{2}$ Department of Biochemistry, Faculty of Science, University of Dschang, Cameroon

${ }^{3}$ Higher Institute of Applied Science, Gulf of Guinea University Institute, Douala Cameroon

${ }^{4}$ Université des Montagnes, Cameroon

${ }^{5}$ Department of Biology, Higher Teacher Training College (ENS) Bambili, University of Bamenda, Cameroon

${ }^{6}$ School of Medical and Biomedical Sciences, National Polytechnic University Institute Bamenda, Cameroon

7Université de Bamenda, Cameroon

${ }^{*}$ Corresponding author: Leonard Fonkeng Sama, Higher institute of Applied Science, Gulf of Guinea University Institute, Douala, Cameroon, Tel: +696072042; E-mail: safole2000@yahoo.fr

Received date: February 13, 2020; Accepted date: February 24, 2020; Published date: February 29, 2020

Citation: Michel N, Sama LF, Kamgue OG, Tchenkam VP, Wam EC, et al. (2020) Seroprevalence of Toxoplasma gondii IgG and IgM Antibodies and Associated Risks Factors in Tuberculosis Patients Admitted at the Bamenda Regional Hospital, NW Cameroon. Arch Clin Microbiol Vol. 11 No. $1: 104$.

\section{Abstract}

Background: Toxoplasmosis is a zoonotic disease with a worldwide distribution amongst warm-blooded animals and can affect anyone in contact with the parasitic oocysts or tissue cysts. Tuberculosis (TB) and T. gondii coinfection is a serious public health problem to the health of these patients in developing countries. We determined the seroprevalence of Toxoplasma gondii IgG and IgM antibodies and associated risk factors among newly diagnosed sputum positive pulmonary TB patients.

Materials and methods: This was a cross sectional study including 158 TB patients. Laboratory analyses were based on quantification of anti T.gondii $\lg M$ and $\lg G$ antibodies test using sandwich ELISA. A questionnaire captured known risk factors for toxoplasmosis among participants. Risk factors for toxoplasmosis were analyzed in a binary logistic model. The results presented as odds ratios were used to assess association of toxoplasmosis and potential risk factors. A p-value $<0.05$ was considered statistically significant.

Result: Of the 158 participants, 87.97\% [139/158] were seropositive for Toxoplasma gondii $\operatorname{lgM}$ and $/ g \mathrm{G}$ antibodies. Eating cat meat $[P=0.009, \quad O R=4.2498$, $95 \% \mathrm{Cl}=1.4300-11.1997]$ and water source $[\mathrm{P}=0.026$, $\mathrm{OR}=5.4983, \mathrm{Cl}=1.2189-23.5827]$, were significant risk factors associated with $T$. gondii infection. We noted a threefold increase in the risk of toxoplasmosis among TB patients having farming as occupation.
Conclusion: The prevalence of toxoplasmosis IgM and IgG antibodies among sputum positive pulmonary TB patients in the Bamenda Regional Hospital, North West Cameroon was found to be $87.97 \%$. The principal risk factor associated with Toxoplasma gondii among TB patients was consumption of Cat meat and untreated water sources.

Keywords: Toxoplasmosis; Seroprevalence; IgG; IgM; Tuberculosis; Cameroon

\section{Introduction}

One third of the world population has been estimated to be infected with Toxoplasma gondii (T. gondii) parasite [1]. Mostly it does not cause serious illness in healthy adults, but causes severe diseases in immune-compromised patients [2]. In immune-competent individuals, effective immune response produces a balance for both parasite and host survival but does not eradicate the infection. Weakness of the host immune function may allow reactivation of actively replicating tachyzoites, sometimes and results in extensive organ damage [3]. Tuberculosis (TB) remains a major cause of morbidity and mortality worldwide in spite of great effort for eradication. Globally, there were an estimated 9.27 million incidences of TB and new infections that occurred at a rate of one per second $[4,5]$. About $33 \%$ of the world population infected with Mycobacterium tuberculosis ( $M$. tuberculosis) resides in developing countries including Cameroon. Cameroon is one of the countries where the prevalence of TB is still high with no prevalence since 2012. The WHO estimated in 2012 that the rate of mortality due to TB in Cameroon was $29 / 100,000$ 
excluding HIV and the prevalence of all forms including HIV positive was $319 / 100,000$ and the rate of incidence including HIV positive was $338 / 100,000$ inhabitants. The increasing number of multi-drug resistant, extensively drug-resistant and extremely resistant strains of $M$. tuberculosis made the control of the tuberculosis spread more difficult [6]. Both TB and parasitic diseases are infectious diseases causing serious harm to humans with an overlap in endemic regions, which may lead to frequent co-infection in these areas. Cases of co-infection of TB with intracellular parasites were reported as with malaria [7,8], visceral leishmaniasis [9,10], and T. gondii [11,12]. Hwang and colleagues [13] reported a cerebral toxoplasmosis case with disseminated tuberculosis in an immune-competent patient. In the cases of co-infection, modification of the immune response was suggested [14-16]. Oxidative stress was recorded, and implicated in the pathogenesis of both TB $[17,18]$, and toxoplasmosis [19]. The response of the immune system against infections includes the generation of reactive oxygen species (free radicals) which are toxic to human tissues and cells. However, no studies on the prevalence of $T$. gondii among TB have been conducted in our locality. The aim of this study was therefore to determine the seroprevalence of anti $T$. gondii antibodies in TB patients and the possible associated risks factors.

\section{Materials and Methods}

\section{Study design}

A cross-sectional study was carried out from October 2015 and April, 2016 at Bamenda Regional Hospital, North West Region, Cameroon.

\section{Study site and population}

The Bamenda Regional Hospital, is a public health care. It is located in Bamenda, the capital City of the North West Region of Cameroon. The hospital was opened in 1956 by Sir Roberts the then British High Commissioner based in Lagos Nigeria. It was given the status of a 3 rd level reference health institution for the North West in 2009. This hospital has a TB unit and one of the two TB reference laboratories in Cameroon. It equally has a TB treatment center, HIV treatment center, and the majority of services rendered are in the domains of gynecology, orthopedics, radiology, dialyses and general surgery.

Participants to the study were TB patients admitted at the TB ward of the Bamenda Regional Hospital who duly provided consent by signing or placing their thumbprint on the consent form.

\section{Questionnaire administration and sample collection}

Participants of this study were each provided with a structured questionnaire to fill. Those who could not read were assisted to fill the questionnaires by the laboratory technician or care nurse. The questionnaires contained simple closed ended questions regarding known risk factors of Toxoplasma exposure in addition to socio-demographic information.

Five millilitres of venous blood were collected into a dry tube and allowed to clot completely before centrifugation at $3000 \mathrm{rpm}$ for 15 minutes at $4^{\circ} \mathrm{C}$ to obtain serum. Serum was separated from the clot into tightly screwed microfuge tubes and stored at $-25^{\circ} \mathrm{C}$. These frozen sera were later tested for the presence of Toxoplasma gondii antibodies.

\section{Detection of pulmonary tuberculosis}

Diagnosis of TB was done by direct Ziehl Neelsen staining of sputum samples for detection of acid fast bacilli and Lowenstein Jensen culture for isolation of M. tuberculosis [20].

\section{Serological test for T. gondii antibodies}

The presence of $T$. gondii antibodies in the participants' sera was determined using an indirect Enzyme-Linked Immunosorbent Assay (ELISA). This was done using the AccuDiag $^{\mathrm{TM}}$ Toxo IgM and IgG ELISA Kits (The Diagnostic Automation/Cortez Diagnostics, Inc. Toxoplasma gondii [Toxo] IgM and IgG Enzyme-Linked Immuno-sorbent Assay [ELISA]). The Toxo IgM ELISA Kits had a specificity of $100 \%$ and a sensitivity of $100 \%$, while the Toxo IgG ELISA Kits had a specificity of $100 \%$ and a sensitivity of $95.3 \%$. Calibrator and controls were run with each test assay. The optical densities (OD) obtained were used to calculate the cut-of calibrator value and the Immune Status Ratio (ISR). The interpretation of results was done with respect to the ISR values. For IgM, a sample with $O D \leq 0.90$ was considered negative, $O D \geq 1.10$ was considered positive, and $\mathrm{OD}=0.91-1.09$ was considered indeterminate. For IgG, a sample with OD $<0.90$ was considered negative, $\mathrm{OD}>1.10$ was considered positive, and OD within 0.91-1.09 was considered indeterminate.

\section{Ethical consideration}

Ethical clearance for this study was obtained from the Ethics Review and Consultancy Committee of the Cameroon Bioethics Initiative (CAMBIN) under the reference number CBI/370/ERCC/CAMBIN of August 18th, 2015. An authorization to collect and analyze blood samples was also obtained from the Bamenda Regional Hospital Institutionalized Review Board (IRB). All participants were duly informed of the study goals, procedures, potential harm and benefits, cost as well as the finality of the study. They willingly provided informed consent either by signing or placing their thumbprint on the consent form after being satisfied with responses to all questions asked the investigator. Patient less than 21 years provided assent and consent from guardian was also sought for these patients. Information was provided in English, French or interpreted in the local dialect by a volunteer independent of the study team. Participants' blood samples and results were anonymised. Left over blood samples were destroyed according to hospital biosafety procedures. 


\section{Data management and statistical analysis}

Data were entered into Microsoft Excel program and then transferred to Epi Info 3.54 statistical program. The seroprevalence of toxoplasmosis was calculated as the proportion of serologically positive anti $T$. gondii samples among all samples tested at $95 \%$ confidence interval $(\mathrm{Cl})$. A simple and multivariate logistic regression model was used to investigate the association between the potential risk factors for toxoplasmosis as defined by seropositivity for Toxoplasma gondii antibodies of any kind. Variables used in the multiple regression were selected through step-wise backward elimination using a $20 \%$ cut-of ( $p$ to remove). The strength of associations was measured using the odds ratio (OR) at $95 \%$ $\mathrm{Cl}$. The Chi-square test was used for group comparisons. Statistical significance was set at $5 \%$ and all the associations that showed a $p<0.05$ were considered significant.

\section{Results}

Out of the 158 participants that were recruited in this study, $50.63 \%$ (80/158) were males while $49.37 \%$ (78/158) were females. The mean age of the participants was $37.07 \pm 11.94$ years with minimal being 11 years and the maximal 80 years. The majority of the participant was aged between 31 and 40 years (53/158, 33.54\%). Amongst all the participants, $16.46 \%$ (26/158) had not attended school, while $46.84 \%$ (74/158), $29.11 \%(46 / 158)$ and $6.96 \%(11 / 158)$, had primary, secondary and higher levels of education. Only 3.16\% (5/158) knew about toxoplasmosis. Those participants who lived in tile, cemented and non-cemented floor houses were $6.96 \%$ (11/158), 84.81\% $(134 / 158)$ and $8.23 \%(13 / 158)$ respectively. Among the study participants, $81.02 \%(128 / 158)$ eat bush meat, $15.19 \%$ $(24 / 158)$ eat cat meat, $10.76 \%(17 / 158)$ consume raw milk, and only $3.79 \%(6 / 158)$ had cats in their homes. Regarding the participants residential area, $71.52 \%(113 / 158)$ of the study participants lived in an urban area, while $28.48 \%$ (45/158) lived in a rural area. Out of the 158 participant recruited in this study, 55.69\% (88/158) were HIV-positive and $44.31 \%$ (70/158) were HIV-negative (Table 1).

Table 1 General characteristic of study participants.

\begin{tabular}{|c|c|}
\hline Characteristic & Number (\%) \\
\hline \multicolumn{2}{|l|}{ Age category } \\
\hline$<21$ & $6(3.79 \%)$ \\
\hline $21-30$ & $40(25.32 \%$ \\
\hline $31-40$ & $53(33.54 \%)$ \\
\hline $41-50$ & $35(22.15 \%)$ \\
\hline $51-60$ & $13(8.23 \%)$ \\
\hline$>60$ & $11(6.96 \%)$ \\
\hline \multicolumn{2}{|c|}{ Level of education } \\
\hline None & $26(16.46 \%)$ \\
\hline Primary & $74(46.84 \%)$ \\
\hline Secindary & $46(29.11 \%)$ \\
\hline High education & $12(7.59 \%)$ \\
\hline \multicolumn{2}{|c|}{ Knowledge of toxoplasmosis } \\
\hline Yes & $5(3.16 \%)$ \\
\hline No & $153(96.84 \%)$ \\
\hline \multicolumn{2}{|l|}{ House floor type } \\
\hline Tile & $11(6.96 \%)$ \\
\hline Cemented & $134(84.81 \%)$ \\
\hline Non-cemented & $13(8.23 \%)$ \\
\hline \multicolumn{2}{|c|}{ Consumption of Bush meat } \\
\hline Yes & $128(81.02 \%)$ \\
\hline No & $30(18.98 \%)$ \\
\hline
\end{tabular}




\begin{tabular}{|c|c|}
\hline \multicolumn{2}{|c|}{ Consumption of cat meat } \\
\hline Yes & $24(15.19 \%)$ \\
\hline No & $134(84.81 \%)$ \\
\hline \multicolumn{2}{|c|}{ Consumption of chicken } \\
\hline Yes & $155(98.10 \%)$ \\
\hline No & $3(1.90 \%)$ \\
\hline \multicolumn{2}{|c|}{ Consumption of community water } \\
\hline Yes & $69(43.67 \%)$ \\
\hline No & $89(56.33 \%)$ \\
\hline \multicolumn{2}{|c|}{ Consumption of row milk } \\
\hline Yes & $17(10.76 \%)$ \\
\hline No & $141(89.24)$ \\
\hline \multicolumn{2}{|c|}{ Residential area } \\
\hline Rural & $45(28.48)$ \\
\hline Urban & $113(71.52 \%)$ \\
\hline \multicolumn{2}{|c|}{ Consumption of unwashed vegetables } \\
\hline Yes & $96(60.76 \%)$ \\
\hline No & $62(39.24 \%)$ \\
\hline \multicolumn{2}{|c|}{ Cats at home } \\
\hline Yes & $6(3.79 \%)$ \\
\hline No & $152(96.21 \%)$ \\
\hline \multicolumn{2}{|c|}{ HIV status } \\
\hline Positive & $88(55.69 \%)$ \\
\hline Negative & $70(44.31 \%)$ \\
\hline
\end{tabular}

Prevalence of antiToxoplasma antibodies in the study population

The combined seroprevalence of anti $T$. gondii antibodies among the 158 TB patients in our study area was calculated to be $87.97 \%$ (139/158). Among the seropositive patients, 88 were seropositive for IgG antibodies, 116 were seropositive for
IgM antibodies, and 65 were seropositive for both IgG and IgM antibodies giving a prevalence of $55.70 \%, 73.42 \%$ and $41.14 \%$ respectively. Of the seropositive patients $47(58.75 \%)$, $61(76.25 \%)$ and $35(43.75 \%)$ males were positive for $\operatorname{lgG}, \operatorname{lgM}$, and IgM and IgG respectively while 41(52.56\%), 55(70.51\%) and $30(38.46 \%)$ females were positive for $\lg$, IgM, and IgM and IgG respectively (Table $\mathbf{2}$ ).

Table $\mathbf{2}$ Seroprevalence of antibodies to Toxoplasma gondii according to sex.

\begin{tabular}{|c|c|c|c|c|c|c|c|c|c|}
\hline Toxo Status & $\lg G$ & Male & Female & $\lg M$ & Male & Female & $\lg M$ and $\lg G$ & Male & Female \\
\hline Positive & $\begin{array}{l}88 \\
(55.7 \%)\end{array}$ & $47(58.75 \%)$ & $\begin{array}{l}41 \\
(52.56 \%\end{array}$ & $\begin{array}{l}116 \\
(73.42 \%)\end{array}$ & $\begin{array}{l}61 \\
(76.25 \%)\end{array}$ & $\begin{array}{l}55 \\
(70.51 \%)\end{array}$ & $65(41.14 \%)$ & $\begin{array}{l}35 \\
(43.75 \%)\end{array}$ & $30(38.46 \%)$ \\
\hline Negative & $\begin{array}{l}59 \\
(37.34 \% \\
)\end{array}$ & $29(36.25 \%)$ & $\begin{array}{l}30 \\
(38.46 \%)\end{array}$ & $\begin{array}{l}30 \\
(18.98 \%)\end{array}$ & $\begin{array}{l}12 \\
(15.00 \%)\end{array}$ & $\begin{array}{l}18 \\
(23.08 \%)\end{array}$ & $93(58.86 \%)$ & $\begin{array}{l}45 \\
(56.25 \%)\end{array}$ & $48(61.54 \%)$ \\
\hline Equivocal & $\begin{array}{l}11 \\
(6.96 \%)\end{array}$ & $4(5 \%)$ & $7(8.98 \%)$ & $12(7.60 \%)$ & $7(8.75 \%)$ & $5(6.41 \%)$ & - & - & - \\
\hline Total & $\begin{array}{l}158 \\
(100 \%)\end{array}$ & 80 & 78 & $158(100 \%)$ & 80 & 78 & 158 & 80 & 78 \\
\hline
\end{tabular}


Of the 88 patients that were HIV positive, $68.18 \%(60 / 88)$ were seropositive for anti T. gondii antibodies. Among the HIV seropositive patients, 40 were seropositive for IgG antibody, 51 were seropositive for IgM antibody, and 31 were seropositive for both IgG and IgM antibodies giving a prevalence of $45.45 \%, 57.95 \%$ and $35.23 \%$ respectively. Of the
HIV positive seropositive patients to anti $T$. gondii antibodies $24(52.17 \%), 25(54.35 \%)$ and $18(39.13 \%)$ males were positive for IgG, IgM, and IgM and IgG respectively while $16(38.10 \%)$, 26(61.90\%) and $13(30.95 \%)$ females were positive for IgG, IgM, and IgM and IgG respectively (Table 3 ).

Table 3 Seroprevalence of antibodies to Toxoplasma gondii among HIV positive.

\begin{tabular}{|c|c|c|c|c|c|c|c|c|c|}
\hline HIV positive & $\lg \mathbf{l}+$ & Male & Female & $\lg M+$ & Male & Female & $\lg M+$ and $\lg G+$ & Male & Female \\
\hline Positive & $\begin{array}{l}40 \\
(45.45 \%)\end{array}$ & $\begin{array}{l}24 \\
(52.17 \%)\end{array}$ & $16(38.10 \%)$ & $\begin{array}{l}51 \\
(57.95 \%)\end{array}$ & $\begin{array}{l}25 \\
(54.35 \%)\end{array}$ & $26(61.90 \%)$ & $31(35.23 \%)$ & $\begin{array}{l}18 \\
(39.13 \%)\end{array}$ & $13(30.95 \%)$ \\
\hline Negative & $\begin{array}{l}48 \\
(54.55 \%)\end{array}$ & $\begin{array}{l}22 \\
(47.83 \%)\end{array}$ & $26(61.90 \%)$ & $\begin{array}{l}37 \\
(42.05 \%)\end{array}$ & $\begin{array}{l}21 \\
(45.65 \%)\end{array}$ & $16(38.10 \%)$ & $57(64.77 \%)$ & $\begin{array}{l}28 \\
(60.87 \%)\end{array}$ & $29(69.05 \%)$ \\
\hline Total & 88 & 46 & 42 & 88 & 46 & 42 & 88 & 46 & 42 \\
\hline
\end{tabular}

The seroprevalence of antibodies to $T$. gondii was significantly different $(\mathrm{P}=0.002)$ in general study population $87.97 \%$ (139/158) than in HIV-positive 68.18\% (60/88). The seroprevalence of anti $T$. gondii IgG antibody in the general study population was $55.70 \%(88 / 158)$, higher than the $45.45 \%(40 / 88)$ in HIV-positive individuals ( $P=0.38)$. Also the seroprevalence of anti $T$. gondii IgM antibody in the general study population was $73.42 \%(116 / 158)$, higher than in HIVpositive individuals $57.95 \% \quad(51 / 88) \quad(P=0.26)$, while the seroprevalence of anti $T$. gondii IgG and IgM in the general study population was $41.14 \%(65 / 158)$, higher than in HIVpositive individuals $35.23 \%(31 / 88)(\mathrm{P}=0.54)$.

A total of $58.75 \%(47 / 80)$ males of the general study population were positive for anti $T$. gondii IgG antibody, slightly higher than $52.17 \%(24 / 46)$ of the HIV positive males $(P=0.7)$, while $76.25 \%(61 / 80)$ males of the general study population were positive for anti $T$. gondii IgM antibody, slightly higher than $54.35 \%(25 / 46)$ of the HIV positive males $(P=0.26)$. 43.75\% (35/80) males were positive for anti $T$. gondii IgG and IgM antibodies, slightly higher than $39.13 \%(18 / 46)$ HIV positive males ( $\mathrm{P}=0.7)$. In addition, $52.56 \%(41 / 78)$ females of the general study population were positive for anti $T$. gondii IgG antibody slightly higher than $38.10 \%$ (16/42) HIV positive females $(P=0.3)$, while $70.51 \%(55 / 78)$ females of general study population were positive for anti $T$. gondii IgM antibody, slightly higher than $61.90 \%$ (26/42) HIV positive females ( $P=0.67)$. 38.46\% (30/78) females were positive for anti $T$. gondii IgG and IgM antibodies, slightly higher than $30.95 \%$ (13/42) HIV positive females ( $P=0.57)$.

\section{Prevalence of signs and symptoms Toxoplasma gondii in the study population}

Of the 139 participants that were diagnosed seropositive for anti T. gondii antibodies, $29.75 \%$ complained to be suffering or to have suffered from chronic headache, $28.48 \%$ of fever, $20,89 \%$ of eye disorder, $13.92 \%$ of lymph node swellings and $6.98 \%$ of Encephalitis (Table 4).
Table 4 Prevalence of signs and symptoms of Toxoplasma gondii amongst TB population.

\begin{tabular}{|l|l|l|}
\hline Signs and symptoms & Number & Proportion (\%) \\
\hline Chronic headache & 47 & 29.75 \\
\hline Fever & 45 & 28.48 \\
\hline Eye disorder & 33 & 20.89 \\
\hline Lymph node swelling & 22 & 13.92 \\
\hline Encephalitis & 11 & 6.96 \\
\hline
\end{tabular}

\section{Risk factors for toxoplasma seropositivity}

As shown in Table 5, simple logistic regression analysis with suspected variables indicated that the consumption of cat meat $(P=0.0092)$ and water sources $(P=0.026)$ were predictors of toxoplasmosis seropositivity irrespective of the antibody type. However, results of multiple logistic regression analysis with selected variables as shown in Table 6 showed that, the was no independent predictor of toxoplasmosis seropositivity irrespective of the antibody type.

\section{Discussion}

Toxoplasmosis is a curable but potentially deadly disease [21]. Infection with the protozoan parasite Toxoplasma gondii has been proven to be one of the most common parasitic infections of man and other warm-blooded animals over the years [22]. This study sought to investigate Toxoplasma infection, as evidenced by anti-Toxoplasma antibodies in the serum of tuberculosis patients at the Bamenda Regional hospital in the North West Region of Cameroon. The seroprevalence of anti $T$. gondii antibodies among TB patients in this study was $87.97 \%$. This prevalence was high compared to the $67.4 \%$ obtained among TB patients in Egypt [23], and the $25 \%$ obtained among TB patients in Sudan [24]. This high prevalence obtained in this study compared to the studies carried out in Egypt and Sudan could be due to the difference at the level of the sample size which was high in our study (154 participants) compared to that in Sudan and Egypt which had 
64 and 43 participants respectively. Also, the technic used for the diagnosis (in Sudan Latex Agglutination Test [LAT] was used for the diagnosis) could have accounted for this difference. In addition, the high prevalence could be attributed to high consumption of bush meat (Table 1). It has been proven that the seroprevalence rates across continents are high in humans due to animals [25], consequent oocysts increase and high consumption of unwashed vegetables as was the case in our study area. The prevalence obtained in our study was also high compared to that obtained among women of child bearing age in Njinikom by Wam and colleagues (54.5\%) [26], in Central Ethiopia (85.3\%) [27], among pregnant women in Yaounde (77.1\%) [28], in Douala (78.6\%) [29], the $71.8 \%$ observed among pregnant women in Limbe [30]. These geographic differences in prevalence rates may be explained by differences in rural/urban setting since exposure and the main sources of infection appear to be the same. This might explain differences in risk factors of Toxoplasma seropositivity as well as climatic changes. Our study population was mainly from an urban area. The seroprevalence of anti $T$. gondii IgG antibody in female patients was $52.56 \%(41 / 78)$, slightly lower than $58.75 \%(47 / 80)$ of the males though not significantly different $(P=0.67)$. This is significantly important to public health. This result was similar to that obtained in Germany where the prevalence of toxoplasmosis among females was not different compared to males [30] and indicates that men are more prone to $T$. gondii infection than women.

The seroprevalence of anti $T$. gondii antibody in HIV-positive participants was $68.18 \%(60 / 88)$. This was not significantly different from the $80.61 \%(79 / 98)$ obtained in the HIVnegative group in this same study population $(P=0.75)$. This result was not similar to the $47.8 \%$ (43/90) obtained among HIV/AIDS patients in Njinikom [26]. However, another study in Ethiopia showed a significantly higher prevalence of antiToxoplasma gondii antibodies (87.4\% vs. $70.29 \%, \mathrm{P}=0.003)$ in HIV-positive pre-antiretroviral therapy (pre-ART) individuals than in HIV-negative blood donors [31]. Of the 139 patients diagnosed positive for Toxoplasma antibodies, the most common symptoms they complained to be having or to have suffered from were chronic headache (29.75\%), fever (28.48\%), eye disorders (20.89\%), lymph node swellings $(13.92 \%)$, and encephalitis (6.96\%). These results corroborate to the symptoms cited by Sarman, 2016 [32].

Univariate analysis showed that the consumption of cat meat $(P=0.009)$, and water source $(P=0.026)$, were significant risk factors associated with $T$. gondii infection (Table 5), whereas in multivariate analysis, no independent significant risk factor was associated with $T$. gondii infection (Table 6). Similar results have been observed in studies done in Mexico [33], Ethiopia [31], Sudan [34], Douala-Cameroon [35], and Thailand [36]. Although domestic cats are probably the major source of contamination [37,38], cat ownership and contact with cats were not found to be significantly associated with $T$. gondii infection $[39,40]$. Indeed, only $3.79 \%$ of the total study population reported having cats at home. Sporulated oocysts survive in moist soil for months to years [41,42]. This may justify why farming was found to be associated to $T$. gondii infection.
Table 5 Simple Logistic regression with suspected variables.

\begin{tabular}{|c|c|c|c|}
\hline Variables & Groups & OR (95\%) Cl & P-Value \\
\hline \multirow[b]{2}{*}{ Sex } & Male & \multirow[b]{2}{*}{$1.20(0.35-1.98)$} & \multirow[b]{2}{*}{0.684} \\
\hline & Female & & \\
\hline \multirow[b]{2}{*}{ Residential area } & Rural & \multirow[b]{2}{*}{$1.08(0.41-3.80)$} & \multirow[b]{2}{*}{0.873} \\
\hline & Urban & & \\
\hline \multirow[b]{4}{*}{ Age group } & $<21$ & \multirow[b]{2}{*}{ NA } & \multirow[b]{2}{*}{0.175} \\
\hline & $21-40$ & & \\
\hline & $41-60$ & \multirow[b]{2}{*}{ NA } & \multirow[b]{2}{*}{0.294} \\
\hline & $>60$ & & \\
\hline \multirow[b]{2}{*}{ Level of education } & Primary & & \\
\hline & High & $1.61(0.44-5.87)$ & 0.451 \\
\hline \multirow[b]{2}{*}{ Cat ownership } & Yes & 541929.9 & 0.872 \\
\hline & No & $(>1.0 \mathrm{E} 12)$ & \\
\hline \multirow{4}{*}{$\begin{array}{l}\text { Consumption of Cat } \\
\text { meat }\end{array}$} & Yes & \multirow[b]{2}{*}{$1.5920(0.73-2.65)$} & \multirow[b]{2}{*}{0.33} \\
\hline & No & & \\
\hline & Yes & 4.2498 & $0.009^{*}$ \\
\hline & No & $(1.4300-11.1997)$ & \\
\hline \multirow{2}{*}{$\begin{array}{l}\text { Consumption of bush } \\
\text { meat }\end{array}$} & Yes & 1.0568 & 0.92 \\
\hline & No & $(0.3573-2.7689)$ & \\
\hline Water & Treated & 5.4983 & $0.026^{*}$ \\
\hline sources & $\begin{array}{l}\text { Untreate } \\
\mathrm{d}\end{array}$ & $(1.2189-23.5827)$ & \\
\hline \multirow{2}{*}{$\begin{array}{l}\text { Consumption of raw } \\
\text { vegetables }\end{array}$} & Yes & 0.6569 & 0.369 \\
\hline & No & $(0.2622-1.3835)$ & \\
\hline \multirow[b]{6}{*}{ Occupation } & Farming & $2.960 .65-13.42)$ & 0.143 \\
\hline & $\begin{array}{l}\text { Public } \\
\text { sector }\end{array}$ & $0.40(0.03-4.60)$ & 0.445 \\
\hline & Business & $0.60(0.11-3.13)$ & 0.532 \\
\hline & Student & $1.52(0.41-5.56)$ & 0.524 \\
\hline & $\begin{array}{l}\text { Private } \\
\text { sector }\end{array}$ & $0.82(0.32-2.08)$ & 0.678 \\
\hline & Driving & $1.14(0.24-5.49)$ & 0.873 \\
\hline \multirow[b]{2}{*}{$\begin{array}{l}\text { Consumption of raw } \\
\text { milk }\end{array}$} & Yes & \multirow[b]{2}{*}{$\begin{array}{l}1.2782 \\
4.5397)\end{array} \quad(0.3058-$} & \multirow[b]{2}{*}{0.724} \\
\hline & No & & \\
\hline \multirow{2}{*}{$\begin{array}{l}\text { Toxoplasma } \\
\text { awareness }\end{array}$} & Aware & & \\
\hline & Unaware & $0.82(0.08-7.67)$ & 0.085 \\
\hline \multirow[b]{2}{*}{ HIV Status } & Positive & $1.78(0.73-4.33)$ & 0.203 \\
\hline & Negative & & \\
\hline
\end{tabular}

Table 6 Multiple logistic regressions of selected variables 


\begin{tabular}{|l|l|l|l|}
\hline Variables & Groups & OR (95\%) & P-Value \\
\hline \multirow{2}{*}{ Consumption of cat meat } & Yes & & \\
\cline { 2 - 2 } & No & 0.94 & 0.927 \\
\hline \multirow{2}{*}{ Water sources } & Treated & & \\
\cline { 2 - 2 } & Untreated & \multirow{2}{*}{1.59} & 0.725 \\
\hline
\end{tabular}

Our study however should be interpreted with some caution as it was hospital based involving only TB patients in the hospital at the time of data collection. It is likely that we may obtain different results with increased sample size as well as with TB patients sampled from the Bamenda community at large since some people might be sick but have limited funds to visit the hospital, so do so only when the situation becomes chronic.

\section{Conclusion}

Toxoplasma gondii infection appears to be a public health concern in TB population, with a global antibody seroprevalence of $87.97 \%$ among TB population. In this study, recent infections were found in $73.42 \%$ participants while $41.14 \%$ of the study population was reactivating. No significant difference $(P=0.75)$ exist between the HIV positive and HIV negative population. Consumption of cat meat, water source and farming were observed to be risk factors for $T$. gondii infection among TB patients in the locality of Bamenda North West Region of Cameroon. Only 3.16\% (5/158) of the study participants knew about toxoplasmosis. Education on toxoplasmosis in TB treatment centers and screening for recent Toxoplasma exposure may be strategies for primary prevention of toxoplasmosis and its devastating outcomes among TB patients.

\section{Competing Interests}

The authors declare that they have no conflicts of interest.

\section{Authors' Contributions}

LFS and CBT conceived the study, JNF and OGK carried out sample analysis and data collection, ECW and VPT participate in data management and statistics,

LFS and ECW drafted the manuscript. All authors reviewed the manuscript and approved the final version prior to submission.

\section{Acknowledgements}

We wish to thank all the participants who sacrificed their time and donated their blood for this study. We also thank particularly the Director, and Nurses of Regional Hospital Bamenda for their contributions and assistance during sample collection and analysis.

\section{References}

1. Dubey JP, Jones JL (2008) Toxoplasma gondii infection in humans and animals in the United States. Int J Parasitol 38: 1257-1278.

2. Balasundaram $M B$, Andavar $R$, Palaniswamy $M$, Venkatapathy $N$ (2010) Outbreak of acquired ocular toxoplasmosis involving 248 patients. Arch Ophthal 128: 28-32.

3. Robert-Gangneux F, Dard' ML (2012) Epidemiology of and diagnostic strategies for toxoplasmosis. Clin Microbiol Rev 25: 264-296.

4. World Health Organization (2010) Global tuberculosis control 2010. Geneva: World Health Organization.

5. World Health Organization (2015) Global tuberculosis report 2015. 20th ed. Geneva: WHO.

6. International Diabetes Federation (2013) Diabetes atlas 2013.

7. World Health Organization (2010) Multidrug and extensively drug-resistant TB (M/XDR-TB): 2010 global report on surveillance and response. Geneva: World Health Organization.

8. Chatterjee Bahadur GC (1945) How to treat pulmonary tuberculosis case running concurrently with malaria. Indian Med Rec65: 260-263.

9. Thapa R, Mallick D, Biswas B (2010) Perinatal malaria and tuberculosis co-infection: a case report. Int J Infect Dis 14: e254e256.

10. Escobar MA, Saravia NG, Weigle KA (1996) Concurrent mucosal leishmaniasis and pulmonary tuberculosis. Clin Infect Dis 23: 836-837.

11. Rathnayake D, Ranawake RR, Sirimanna G, Siriwardhane $Y$, Karunaweera N, et al. (2010) Co-infection of mucosal leishmaniasis and extra pulmonary tuberculosis in a patient with inherent immune deficiency. Int J Dermatol 49: 549-551.

12. Schroeder HW, Yarrish RL, Perkins TF, Lee C (1984) Sequential disseminated tuberculosis and toxoplasmosis in a Haitian refugee. South Med J 77: 533-534.

13. Guneratne R, Mendis D, Bandara T, Fernando SD (2011) Toxoplasma, toxocara and tuberculosis co-infection in a four year old child. BMC Pediatr 11: 44.

14. Hwang EH, Ahn PG, Lee DM, Kim HS (2012) Cerebral toxoplasmosis combined with disseminated tuberculosis. J Korean Neurosurg Soc 51: 316-319.

15. Scott CP, Kumar N, Bishai WR, Manabe YC (2004) Short report: modulation of Mycobacterium tuberculosis infection by Plasmodium in the murine model. Am J Trop Med Hyg 70: 144-148.

16. Mueller AK, Behrends J, Hagens K, Mahlo J, Schaible UE, et al. (2012) Natural transmission of Plasmodium berghei exacerbates chronic tuberculosis in an experimental co-infection model. PLoS One 7: e48110.

17. Wild I, Seaman T, Hoal EG, Benade AJ, Van Helden PD (2004) Total antioxidant levels are low during active TB and rise with anti-tuberculosis therapy. UBMB Life 56: 101-106.

18. Awodele O, Olayemi SO, Nwite JA, Adeyemo TA (2012) Investigation of the levels of oxidative stress parameters in HIV and HIV-TB co-infected patients. J Infect Dev Ctries 6: 79-85.

19. Karaman U, Celik T, Kiran TR, Colak C, Daldal NU (2008) Malondial-dehyde, glutathione, and nitric oxide levels in 
Toxoplasma gondii seropositive patients. Korean J Parasitol 46: 293-295.

20. World Health Organization (1998) Laboratory services in tuberculosis control. Part II: microscopy. Geneva: World Health Organization.

21. Negash T, Tilahun G, Medhin G (2008) Seroprevalence of Toxoplasma gondii in Nazareth town, Ethiopia. East Afr J Public Health 5: 211-214.

22. Dubey JP (2010) Toxoplasmosis of animals and humans. 2nd ed. Beltsville: CRC Press.

23. Mervat M, Nairmen N, Fawzy IM, Abeer AEH (2017) Tuberculosis/toxoplasmosis co-infection in Egyptian patients: A reciprocal impact. Asian Pacific Journal of Tropical Medicine 10: 315-319.

24. Habab MY (2015) Prevalence of toxoplasma gondii in Tuberclosis patients in Sudan. International Journal of Innovation and Applied Studies 13: 677-680.

25. Hammond Aryee K, Esser M, Van Helden PD (2014) Toxoplasma gondii seroprevalence studies on humans and animals in Africa. S Afr Fam Pract 56: 119-124.

26. Wam CE, Sama FL, Ali MI, Ebile AW, Aghangu LA, et al. (2016) Seroprevalence of Toxoplasma gondii IgG and IgM antibodies and associated risk factors in women of child-bearing age in Njinikom, NW Cameroon. BMC Res Notes; 9: 406.

27. Abamecha F, Awel H (2016) Seroprevalence and risk factors of Toxoplasma gondii infection in pregnant women following antenatal care at Mizan Aman General Hospital, Bench Maji Zone (BMZ), Ethiopia. BMC Infectious Diseases 16: 460.

28. Ndumbe PM, Andela A, Nkemnkeng-Asong J, Watonsi E, Nyambi $P$ (1992) Prevalence of infections afecting the child among pregnant women in Yaounde, Cameroon. Med Microbiol Immunol 181: 127-130.

29. Nguefack CT, Meumeu IK, Ngaba GP, Kongnyuy E, Njamen TN, et al. (2016) Prevalence and Factors Associated with Toxoplasma Gondii Immunization among Pregnant Women in DoualaCameroon. J Womens Health, Issues Care 5: 6.

30. Ndassi DV, Kamga HLF (2014) The seroprevalence of toxoplasmosis and contributing factors among pregnant women attending antenatal consultation in the Limbe Health District, Cameroon. Afr J Integr Health 04: 31-36.

31. Wilking $H$, Thamm M, Stark K, Aebischer T, Seeber F (2016) Prevalence, incidence estimations, and risk factors of
Toxoplasma gondii infection in Germany: a representative, cross-sectional, serological study. Scientific RepoRts.

32. Walle F, Kebede N, Tsegaye A, Kassa T (2013) Seroprevalence and risk factors for Toxoplasmosis in HIV infected and noninfected individuals in Bahir Dar, Northwest Ethiopia. Parasit Vectors 6: 15 .

33. Sarman S (2016) Congenital toxoplasmosis: Clinical features, outcomes, treatment, and prevention, Trop Parasitol 6: 113-122.

34. Alvarado-Esquivel C, Sifuentes-Alvarez A, Narro-Duarte SG, Estrada-Martínez S, Díaz-García JH, et al. (2006) Seroepidemiology of Toxoplasma gondii infection in pregnant women in a public hospital in northern Mexico. BMC Infect Dis 6: 17.

35. Khalil M, Kodym P, Maly M, Intisar E, Rayah I (2014) Environmental and food habitat risk factors associated with Toxoplasma gondii Infection in rural women in Sudan. Int J Curr Microbiol Appl Sci 3: 208-222.

36. Njunda AL, Assob JCN, Nsagha DS, Kamga HL, Nde PF, et al. (2011) Seroprevalence of Toxoplasma gondii infection among pregnant women in Cameroon. J Public Health Africa 2: e24.

37. Andiappan $\mathrm{H}$, Nissapatorn V, Sawangjaroen N, Chemoh W, Lau YL, et al. (2014) Toxoplasma infection in pregnant women: a current status in Songklanagarind hospital, Southern Thailand. Parasit Vectors 7: 239.

38. Tenter AM, Heckeroth AR, Weiss LM (2000) Toxoplasma gondii: from animals to humans. Int J Parasitol 30: 1217-1258.

39. Dubey JP (2001) Oocyst shedding by cats fed isolated bradyzoites and comparison of infectivity of bradyzoites of the VEG strain Toxoplasma gondii to cat sand mice. J Parasitol 87: 215-219.

40. Dubey JP (2013) The history and life cycle of Toxoplasma gondii. In: Weiss LM, Kim K, editors. Toxoplasma gondii, the model apicomplexan: perspectives and methods, 2nd edn. Waltham, MA: Elsevier 1-14.

41. Martinez E, Mago H, Rocha R, Pacheco M (2002) Epidemiological indings and prevalence of Toxoplasma gondii antibodies in HIVpositive patients in a Venezuelan hospital. Valencia Int Conf AIDS 7-12: 14.

42. Dubey JP, Beattie CP (1988) Toxoplasmosis of animals and man. Boca Raton: CRC Press; 220. 